\title{
Effect of Remineralization Potential of ACP-CPP with Fluoride and ACP-CPP on Enamel Subsurface Lesion in Primary and Young Permanent Teeth: In situ Study
}

\author{
Tavleen Singh ${ }^{1}$, Shalini Garg ${ }^{2}$, Abhishek Dhindsa ${ }^{3}$, Neetu Jain ${ }^{4}$
}

\begin{abstract}
Purpose: To compare the remineralization potential of amorphous calcium phosphate-casein phosphopeptide (ACP-CPP), ACP-CPP with fluoride and placebo group in an in situ model concerning enamel subsurface lesion in primary and young permanent teeth.

Materials and methods: This randomized double-blind crossover in situ study was conducted for 21 days. Fifteen healthy children in the age group of 12-15 years with a mean age of 13.5 years wore acrylic palatal appliances having two rows of four demineralized enamel slabs. The left row consisted of the enamel slabs of primary teeth, and the right row consisted of enamel slabs of young permanent teeth. Changes in the enamel microhardness and surface roughness were assessed using surface microhardness assessment analysis and Scanning electron microscopy in three different groups (group I ACP-CPP with fluoride, group II ACP-CPP, and group III Nonfluoridated toothpaste).

Results: Mean change in microhardness was higher in enamel slabs of primary teeth as compared to enamel slabs of young permanent teeth. Group I (ACP-CPP with fluoride) showed maximum microhardness ( $p$ 0.579). Statistically, the insignificant difference was found between group II (ACP-CPP) ( $p$ 0.739) and group III (non-fluoridated toothpaste) ( $p 0.011)$. SEM evaluation revealed mean scores were minimum at baseline and maximum after demineralization. After remineralization, mean scores were minimum in group I (ACP-CPP with fluoride) (3.94) and maximum in group III (nonfluoridated toothpaste) (6.94).

Conclusions: ACP-CPP with fluoride showed maximum remineralization potential between primary and permanent enamel groups as compared to ACP-CPP alone and nonfluoridated toothpaste.

Keywords: Amorphous calcium phosphate-casein phosphopeptide, Primary teeth, Remineralization, Surface microhardness, Young permanent tooth.

Journal of South Asian Association of Pediatric Dentistry (2018): 10.5005/jp-journals-10077-3012
\end{abstract}

\section{INTRODUCTION}

$\mathrm{P}^{\prime}$ revention of dental caries is always the first line of treatment but once the demineralization has set in, the first basic step is the remineralization of early carious lesions, advocating a biological approach rather than the traditional radical treatment for early subsurface lesions. One of the key elements of a biological approach is the usage and application of remineralizing agents to the tooth ${ }^{1,2}$. Prevention is the most important tool to manage at caries risk tooth surfaces and incipient caries. These lesions should be treated by noninvasive approach remineralization can be achieved effectively with bioavailable calcium, phosphate, and fluoride ions to restore the strength and esthetic appearance of the lesion ${ }^{3,4}$. Therefore, the present study aimed to compare the remineralization potential of CPP-ACP, CPP-ACP with fluoride and placebo group in an in situ model concerning enamel subsurface lesion in primary and young permanent teeth.

\section{Materials and Methods}

\section{Preparation of Enamel Slabs}

This randomized double-blind crossover in situ study was conducted after obtaining clearance from the university ethical committee. Blinding was done by masking the exterior look of the tubes by painting them and labeling $A, B$, and $C$ respectively to all the samples. Sample A was (ACP-CPP with fluoride tooth mousse for local application), sample B was (ACP-CPP tooth mousse for local application), sample $C$ (nonfluoridated toothpaste as a tooth mousse) (Flow chart 1).
1Dentist, ${ }^{2,3}$ Professor, ${ }^{4}$ Assitant Professor

${ }^{1}$ Narula Chest and Dental Care Centre, Kashipur, Uttarakhand, India ${ }^{2}$ Department of Pedodontics and Preventive Dentistry, Sudha Rustagi College of Dental Sciences and Research, Faridabad, Haryana, India

${ }^{3}$ Department of Pedodontics and Preventive Dentistry, Swami Devi Dyal Hospital and Dental College, Barwala, Haryana, India

${ }^{4}$ Department of Pediatric and Preventive Dentistry, Maharishi Markandeshwar College of Dental Sciences and Research, Maharishi Markandeshwar University, Ambala, Haryana, India

Corresponding Author: Shalini Garg, Professor, Department of Pedodontics and Preventive Dentistry, Sudha Rustagi College of Dental Sciences and Research, Faridabad, Haryana, India, Phone: +919215668621, e-mail: shaloosandeep@gmail.com

How to cite this article: Singh T, Garg $S$ et al. Effect of Remineralization Potential of ACP-CPP with Fluoride and ACP-CPP on Enamel Subsurface Lesion in Primary and Young Permanent Teeth: In situ Study. J South Asian Assoc Pediatr Dent 2018;1(2):47-53.

Source of support: Nil

Conflict of interest: None

\section{Preparation of Enamel Slabs}

Enamel specimens of dimensions $4 \mathrm{~mm} \times 3 \mathrm{~mm} \times 2 \mathrm{~mm}$ were obtained using the water-cooled diamond disk from the cervical third of the labial/buccal surface of sound human premolars extracted for orthodontic reasons and primary mandibular incisor teeth and were mounted in the acrylic slab. Baseline surface microhardness (SMH) and scanning electron microscope (SEM) analysis of the slabs for the baseline data were done (Fig. 1).

() The Author(s). 2019 Open Access This article is distributed under the terms of the Creative Commons Attribution 4.0 International License (http://creativecommons. org/licenses/by/4.0/), which permits unrestricted use, distribution, and non-commercial reproduction in any medium, provided you give appropriate credit to the original author(s) and the source, provide a link to the Creative Commons license, and indicate if changes were made. The Creative Commons Public Domain Dedication waiver (http://creativecommons.org/publicdomain/zero/1.0/) applies to the data made available in this article, unless otherwise stated. 


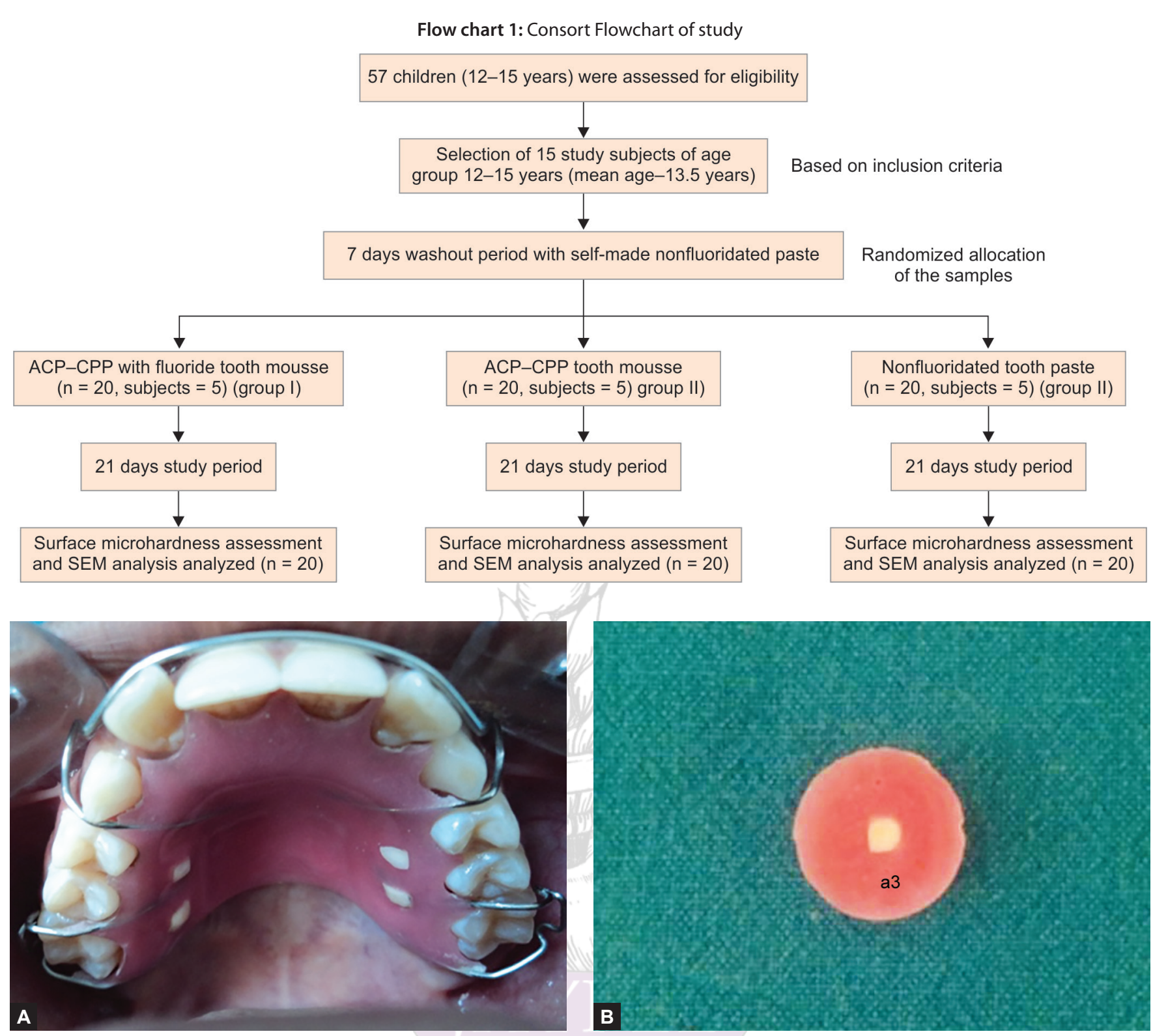

Figs $1 \mathrm{~A}$ and B: (A) Palatal appliance having left a row of deciduous teeth enamel slab and the right row of young permanent teeth enamel slab;

(B) Enamel specimens were mounted on acrylic resin blocks

\section{Creation of Artificial Subsurface Lesion}

Enamel slabs were kept in the plastic vials containing demineralizing solution; $\mathrm{SMH}$ and SEM reading for demineralized enamel slabs were noted. Sixty enamel slabs in subjects were randomly divided into three groups in which each group had 20 slabs.

\section{Fabrication of Intraoral Appliances}

Acrylic palatal appliances containing two rows of 4 demineralized enamel specimens (left row: primary teeth; right row: young permanent teeth) (Fig. 1B).

\section{Subject Recruitment}

Fifteen healthy children in the age group of 12-15 years (mean age- 13.5 years) took part in 21 days study period. The children wore acrylic palatal appliances and changes in the enamel microhardness and surface roughness were assessed using SMH analysis and SEM.
The inclusion criteria for the study were the absence of any clinically detectable carious lesions, children with good general health and those who agreed to brush their teeth with the assigned study products twice a day.

\section{Surface Microhardness Assessment and Demineralization}

Enamel specimens were mounted on acrylic resin blocks, and their outer surfaces were polished flat with $320,420,600$ grades of silicon carbide abrasive papers and the final polishing was completed using $1 \mu$ alumina paste at low speed before obtaining baseline $\mathrm{SMH}$ values (Fig. 1B). Vicker's hardness number (VHN) was determined by making an indentation in each specimen using a square-based diamond pyramid Vicker's indenter under a load of $500 \mathrm{~g}$ for $15 \mathrm{~s}$ (Fig. 2). All specimens were then immersed into demineralized water ( $\mathrm{pH} 2.8$ ) for 5 days and incubated at $37^{\circ} \mathrm{C}$ followed by a second $\mathrm{SMH}$ assessment (Fig. 2). 

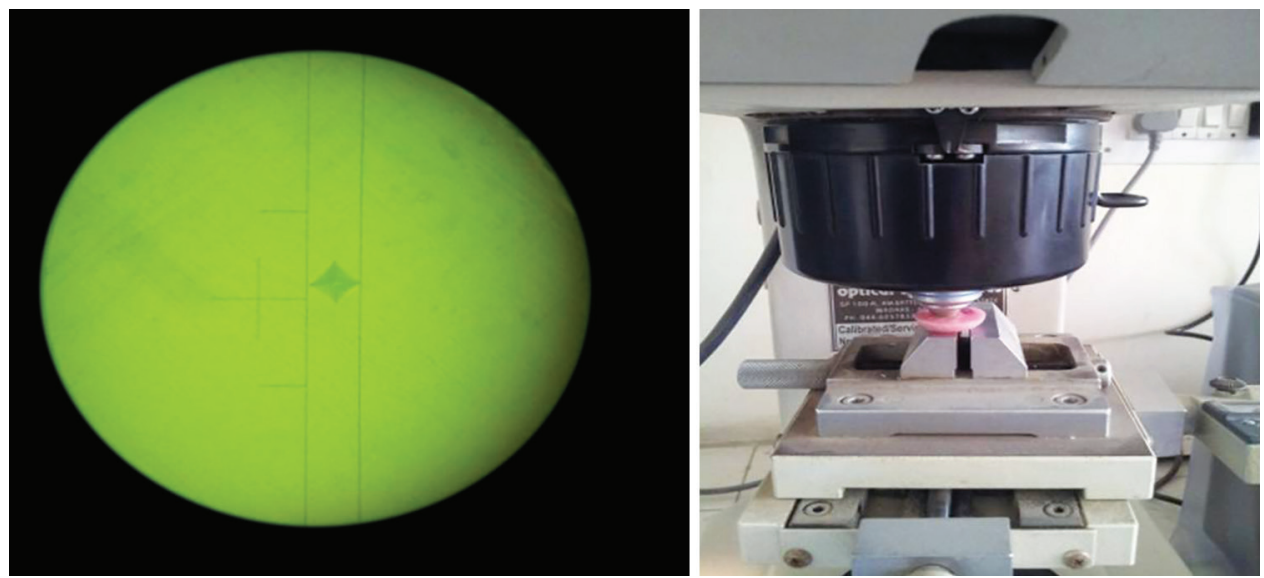

Fig. 2: Vicker's hardness number (VHN) was determined by making an indentation in each specimen using a square-based diamond pyramid

\section{In Situ Remineralization of Demineralized Enamel Specimens}

Pre-reading for VHN for demineralized enamel slabs was noted. For 7 days initial washout period; all the children included in the study were given a nonfluoridated toothpaste for brushing twice per day under supervised conditions with the help of parents. At the end of the washout period, the children were delivered palatal appliance with the demineralized enamel slabs mounted on the palatal surface. Children were given instructions regarding wearing them full day along with the cleaning instructions. During the study period, parents were contacted telephonically to check whether children were following instructions regularly. All testing samples $(n=60)$ were coded and blinded for the investigator and volunteer. Samples were randomly divided via chit method into three groups ( $n=20$ in each group); group I-used sample A for local application, group II-sample B and group III-nonfluoridated toothpaste as mousse. During the study period of three weeks, children brushed their teeth for 2 minutes with appliances in the mouth with the nonfluoridated toothpaste (half the length of toothbrush head). After brushing pea size of respective tooth mousse samples (A, B and C) was applied on enamel slabs with the help of dry finger/cotton tip and instructed to be left undisturbed for 3 minutes and then spread throughout the mouth; to expectorate and avoid rinsing. At the end of the study period ( 21 days), the appliances were taken from children and enamel slabs were removed with the help of acrylic burs, washed with deionized water, and stored in moist conditions in duly labeled plastic vials for SMH and SEM analysis (Fig. 3).

\section{Statistical Analysis}

The microhardness values of different groups were compared using the Kruskal-Wallis test. The micrographs were graded according to 8 parameters that were flatness and smoothness of surface, homogeneous of enamel crystals, crystal irregularity, porosity, micro defects, crystal outline, clogging and fusion of crystals, amorphous shape and disorderly arrangement of crystals on a scale 0-9 (0-baseline value; 9 -lowest value) regarding quality of that parameter; studied by two blinded examiners and interexaminer reliability was observed.

\section{Results}

The percentage changes in surface microhardness values in baseline to demineralization showed no statistically significant difference between enamel slabs of deciduous and young permanent teeth $(p>0.05)$ (Table 1 and Graph 1). Percentage changes in demineralization to remineralization; mean change was higher in enamel slabs of deciduous teeth as compared to enamel slabs of young permanent teeth for overall and group I (ACP-CPP with fluoride).

All enamel slabs in group I (ACP-CPP with fluoride) showed maximum $\mathrm{SMH}$ after remineralization (VHN) 10.36 \pm 14.49 followed by group I $3.02 \pm 2.53$ and group III $1.37 \pm 1.47(p=0.149)$. Both ACP-CPP and ACP-CPP with fluoride tooth mousse were able to remineralize statistically significantly better than placebo tooth mousse $(p=0.001)$. Deciduous enamel slabs in group I showed maximum SMH after remineralization $(\mathrm{VHN})(14.90 \pm 19.13)$ and $(5.81 \pm 5.56)$ followed by group II $(3.18 \pm 3.16)$ and group III 0.67 \pm 0.55 ( $p$ value 0.436 ). In young permanent teeth enamel group I more remineralization was seen followed by groups II and III with percentage change $5.81 \pm 5.56,2.86 \pm 1.86,2.07 \pm 1.77$ respectively. But the difference between them was not statistically significant. SEM evaluation revealed mean SEM scores to be minimum at baseline and maximum after demineralization. After remineralization, mean scores were minimum in group I (3.94) and maximum in group III (6.94). Statistically, intergroup differences were significant $(p<0.001)^{* *}$ (Table 2 and Graph 2).

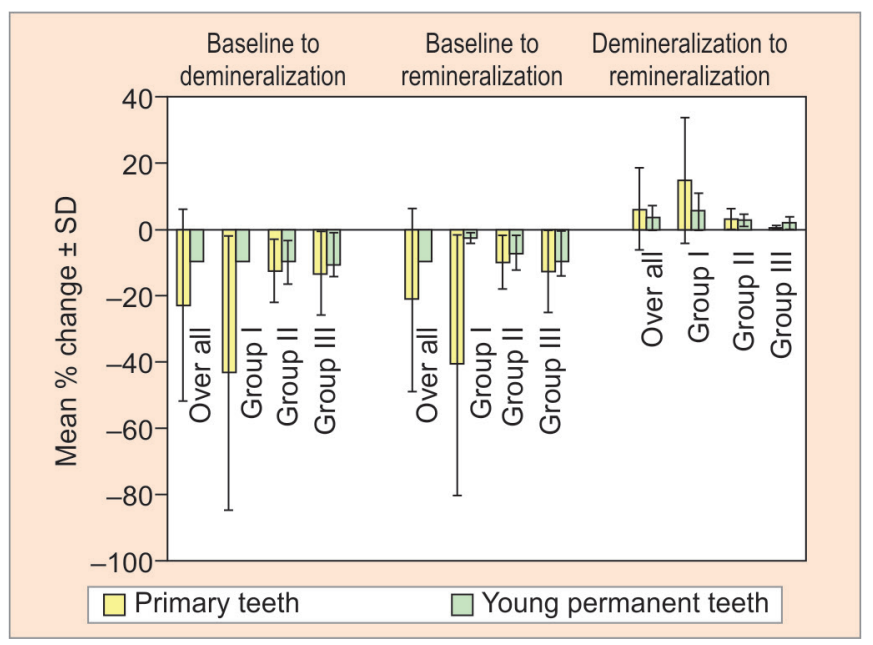

Graph 1: Group wise comparison of $\%$ change in SMH between enamel slabs of deciduous and young permanent teeth at different stages 
Before demineralization
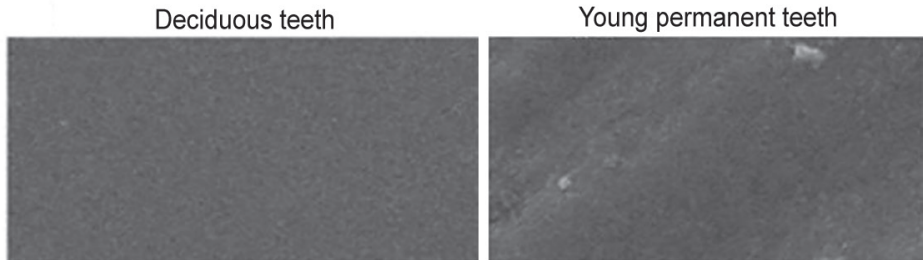

After demineralization
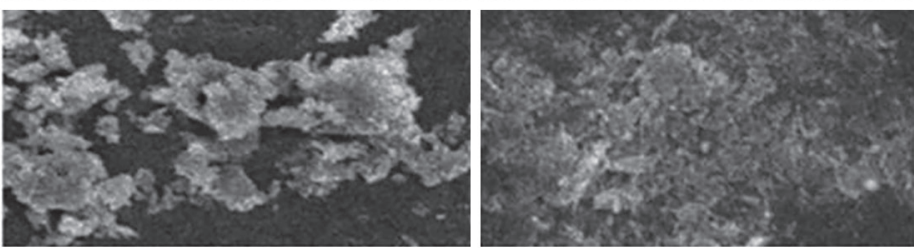

Group I (ACP-CPP with fluoride)
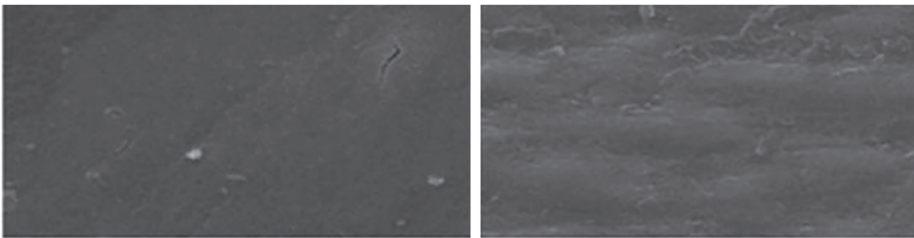

Group II (ACP-CPP)
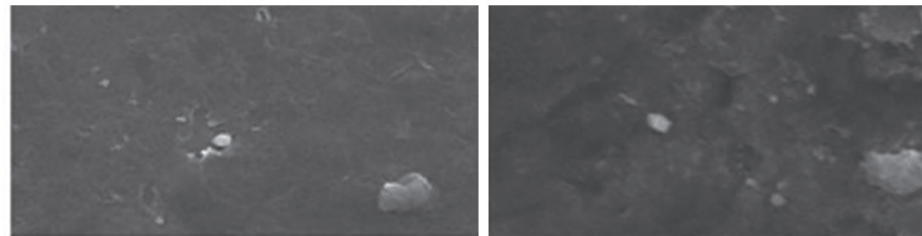

Group III (nonfluoridated tooth paste)
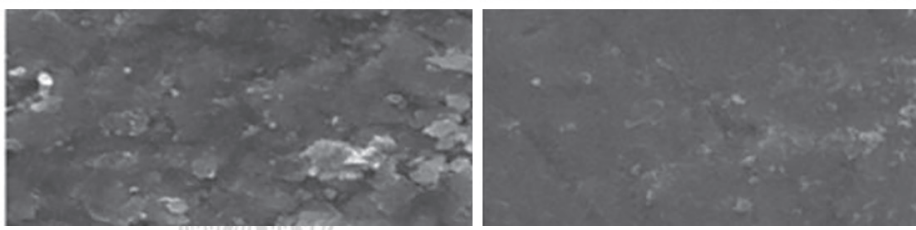

Fig. 3: SEM micrographs of enamel surfaces of deciduous and young permanent teeth

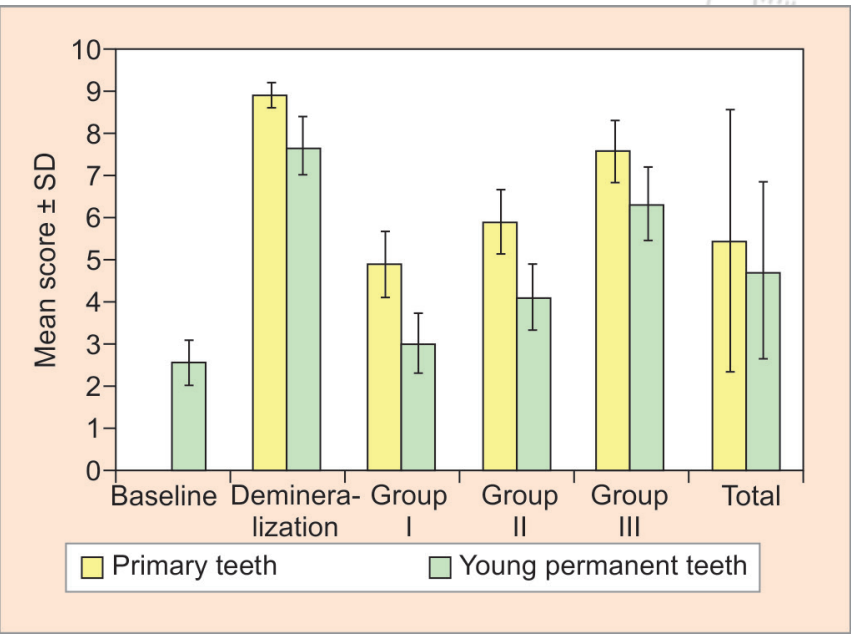

Graph 2: Comparison of SEM scores between enamel slabs of deciduous and enamel slabs of young permanent teeth

\section{Discussion}

Dental caries is a complex form of hard tissue pathology controlled by multiple factors. Cariogenic bacterial count, the status of normal healthy flora, protective salivary factors, dietary sources of fermentable carbohydrates and individual ionic ecosystem of the oral cavity are few of many factors responsible for caries. Subsurface enamel demineralization is the result of complex physical and chemical interaction between the enamel surface and salivary oral environment ${ }^{5-7}$. The main factors known to control the stability of enamel hydroxyapatite are the $\mathrm{pH}$ status and availability of free active calcium, phosphate and fluoride concentrations in oral fluids ${ }^{8,9}$.

Over the last few years, interest has been evoked in preservation and restoration of minerals of dental tissue by using products that can enhance the bioavailability of free active calcium, phosphate, and fluoride ion concentrations in the oral environment ${ }^{10,11}$.

Fluoride is a proven key element in noninvasive management of early noncavitated carious lesions by remineralization and prevention of caries. The ability of fluoride to promote net remineralization is largely dependent on the availability of calcium and phosphate ions ${ }^{12}$. Biomimetic approaches to stabilize available calcium, phosphate, and fluoride ions are therapeutic for noncavitated caries lesions for controlled healing by remineralization. This process is the basis of noninvasive management of initial early carious lesions ${ }^{1}$.

Recently, a range of novel calcium-phosphate-based remineralization delivery systems has been developed for clinical application. CPP-ACP slows the progression of caries as it has an ability to increase the incorporation of fluoride into plaque and to promote enamel remineralization in situ ${ }^{12}$. Many studies on demineralization/remineralization have been conducted in 
Table 1: Group wise comparison of the percentage change in SMH between enamel slabs of deciduous and young permanent teeth at different stages

\begin{tabular}{|c|c|c|c|c|c|c|c|}
\hline \multirow[t]{2}{*}{$\begin{array}{l}\text { S. } \\
\text { No. }\end{array}$} & \multirow[t]{2}{*}{ Time gap } & \multicolumn{2}{|c|}{ Deciduous } & \multicolumn{2}{|c|}{ Young permanent } & \multicolumn{2}{|c|}{$\begin{array}{l}\text { Significance of difference } \\
\text { (Mann-Whitney U test) }\end{array}$} \\
\hline & & Mean & $S D$ & Mean & $S D$ & $Z$ & $p$ \\
\hline \multicolumn{8}{|c|}{ Baseline to demineralization } \\
\hline 1. & Overall & -22.85 & 28.75 & --9.28 & 7.47 & 1.375 & 0.169 \\
\hline \multicolumn{8}{|c|}{ Demineralization to remineralization } \\
\hline 1. & Overall & 6.25 & 12.52 & 3.58 & 3.78 & 0.961 & 0.337 \\
\hline 2. & Group I (ACP-CPP with fluoride) & 14.90 & 19.13 & 5.81 & 5.56 & 0.605 & 0.579 \\
\hline 3. & Group II (ACP-CPP) & 3.18 & 3.16 & 2.86 & 1.86 & 0.378 & 0.739 \\
\hline 4. & Group III (Placebo) & 0.67 & 0.55 & 2.07 & 1.77 & 2.495 & 0.011 \\
\hline
\end{tabular}

Table 2: Comparison of SEM scores between enamel slabs of deciduous and young permanent teeth

\begin{tabular}{|c|c|c|c|c|c|c|c|}
\hline \multirow[t]{2}{*}{ Sl. No. } & \multirow[t]{2}{*}{ Condition } & \multicolumn{2}{|c|}{ Deciduous $(n=9)$} & \multicolumn{2}{|c|}{ Young Permanent $(n=9)$} & \multicolumn{2}{|c|}{$\begin{array}{l}\text { Significance of difference } \\
\text { (Mann-Whitney U test) }\end{array}$} \\
\hline & & Mean & $S D$ & Mean & $S D$ & $z$ & $p$ \\
\hline 1. & Baseline & 0 & 0 & 2.56 & 0.53 & 3.890 & $<0.001$ \\
\hline 2. & Demineralization & 8.89 & 0.33 & 7.67 & 0.71 & 3.218 & 0.001 \\
\hline 3. & Group I (ACP-CPP with fluoride) & 4.89 & 0.78 & 3.00 & 0.71 & 3.404 & 0.001 \\
\hline 4. & Group II (ACP-CPP) & 5.89 & 0.78 & 4.11 & 0.78 & 3.277 & 0.001 \\
\hline 5. & Group III (Placebo) & 7.56 & 0.73 & 6.33 & 0.87 & 2.612 & 0.011 \\
\hline 6. & Total $(n=45)$ & 5.44 & 3.14 & 4.73 & 2.10 & 1.921 & 0.055 \\
\hline
\end{tabular}

young permanent teeth and rarely in deciduous teeth ${ }^{13,14}$. As a pediatric dentist we have to deal more with caries lesions in young permanent and deciduous teeth enamel, so an in situ study was planned to compare the remineralizing potential of CPP-ACP with fluoride tooth mousse CPP-ACP tooth mousse and a placebo tooth mousse in artificially demineralized deciduous and young permanent enamel.

Surface microhardness value and scanning electron microscopy examination to assess changes at an ultrastructural level were selected as a method to assess mineralization of enamel at baseline, after demineralization, and after remineralization. SMH is an indirect technique; however, SEM required the gold coating in which samples once used could not be evaluated again, and hence baseline, demineralization and different type of remineralization studies could be done in separate samples only ${ }^{15,16}$. The clinical part of the study ascertained that the specimens were obtained from a homogeneous population with similar dietary and oral healthcare; as the effect of dietary habits and oral healthcare on demineralization has been reported ${ }^{17}$.

In the present study, after artificial demineralization, mean percentage (VHN) loss of mineralized tissue from primary enamel was more than from young permanent enamel ( $p=0.169)$. As deciduous enamel have greater susceptibility to dissolution during an initial linear stage: $1.5+/-0.5 \times 10(-10) \mathrm{mol} \mathrm{mm}(-2)$ min (-1) compared with $2.6+/-0.5 \times 10(-11) \mathrm{mol} \mathrm{mm} \mathrm{(-2)} \mathrm{min}(1)$ for young permanent enamel ${ }^{13}$. Also the lower level of $\mathrm{Ca}$ and $\mathrm{P}$, thinner thickness and higher numeral density of rods in deciduous enamel as compared to permanent teeth ${ }^{18}$. The mineral content for deciduous enamel is $81.3-94.2 \mathrm{wt} \%$, while it is $97 \%$ in permanent enamel which is close to pure synthetic apatite ${ }^{19,20}$. All this along with more accessible pore volume in partially demineralized deciduous enamel contributes to the subsequent mineral loss which is more in deciduous enamel ${ }^{21}$.

In the present study, group I showed maximum SMH after remineralization followed by groups II and III; which shows that $C P P-A C P$ with fluoride had more potential to remineralize the artificially demineralized tooth enamel $(p=0.149)$. The reason for remineralization in young permanent teeth even in case of control is that there are many different agents within saliva and plaque that serve to protect the tooth surface against caries development. Whereas saliva only could not remineralize excessively demineralized deciduous enamel; may be the localization of remineralizing sites were lost beyond repair and It needs more supply of therapeutic agents for remineralization ${ }^{22}$.

In SEM micrographs visual examination analysis of present study, deciduous enamel showed lowest (highly mineralized) baseline grade (0) value but subsequently for every step showed a higher mean value (indicating higher demineralization) as compared to young permanent enamel, thus indicating that demineralization affects deciduous enamel more severely than young permanent enamel and remineralization is less effective in deciduous enamel as compared to young permanent enamel.

Present study results show the requirement of calcium and phosphate ions for effective remineralization during therapeutic fluorides application. CPP-ACP containing fluoride dentifrices help the localization process of calcium and phosphate ions with fluoride ions at the tooth surface indicating the formation of some CPP-ACP/F nano-complexes like structures ${ }^{23}$. High availability of calcium, phosphate, and fluoride ions at the tooth-oral fluid interaction surface junction drives positive diffusion of these ions into the enamel, leading to increased the activity of ions in the subsurface lesion fluid. This may result in more stable remineralized 
fluoride containing crystal lattice formation at the site of action in the mineral phase.. Hence, the ability to deliver calcium, phosphate, and fluoride ions in the correct molar ratio deep into the subsurface lesion may be attributable to the ability of the CPP to localize and stabilize the ions at the tooth surface in the correct molar ratio (Ca:PO4:F $=5: 3: 1)^{23}$. In the presence of a small quantity of fluoride (0.03-0.08 ppm) within biofilms, saliva, and artificial calcifying fluids, remineralization is favored over demineralization ${ }^{24}$.

The physical characteristics of saliva like flow rate, buffering capacity, antimicrobial activity, microorganism aggregation and clearance from the oral cavity, immune system, and calcium phosphate binding proteins act and sum up collectively to inhibit or reverse demineralization of exposed tooth surfaces ${ }^{25}$. Excessive demineralization in deciduous teeth causes diffusion of rods and easy invasion of bacteria through increased pores size as observed in SEM micrographs. With the opening of pathways, bacteria can invade deep, and further biofilm invasion causes demineralization; also remineralization is not possible after its nucleation sites are lost completely. Furthermore, to create conditions for saturation/ supersaturation, there is a requirement of the supply of a significant amount of minerals from saliva. Therefore, the role of CPP-ACP with fluoride becomes a must as remineralization is not possible only with plaque control ${ }^{26,27}$.

Remineralization is less effective in deciduous teeth as compared to young permanent teeth due to unfavorable mineral content ratios like a large number of elements like carbonate, water, and magnesium making it more porous ${ }^{28}$. Incorporation of fluoride and calcium in surface enamel along with the alternate process of demineralization and remineralization, the new improved more resistant and less permeable remineralized enamel surface form is achieved which has less water with more favorable mineral content. This favorable incorporation of minerals in crystal lattice leads to more caries-resistant and less soluble enamel form ${ }^{29}$.

In conclusion deciduous enamel loose more mineralized tissue during artificial demineralization. In situ results of the present study suggest that supervised twice daily use of "CPP-ACP plus fluoride" tooth Mousse may be superior to "CPP-ACP" alone tooth mousse when compared as remineralizing agent for artificially demineralized deciduous and young permanent tooth enamel while using nonfluoridated toothpaste.

\section{References}

1. Cochrane NJ, Cai F, Huq NL, Burrow MF, Reynolds EC. New approaches to enhanced remineralization of tooth enamel.J Dent Res 2010; 89:1187-1197.

2. Zhang Q, Zou J, Yang R, Zhou X. Remineralization effects of casein phosphopeptide amorphous calcium phosphate crème on artificial early enamel lesions of primary teeth. Int J Paediatr Dent 2011; 21:374381.

3. Doozandeh M, Shafiei F, Ghasempoor $P$, et al. The Effect of the Application Sequence of Casein Phosphopeptide-Amorphous Calcium Phosphate Paste on the Shear Bond Strength of Etch-andRinse Resin Cements to Dentin. J Prosthodont 2019.

4. Abufarwa M, Noureldin A, Azimaie $T$, et al. Preventive effects of carbon dioxide laser and casein phosphopeptide amorphous calcium phosphate fluoride varnish on enamel demineralization: A comparative, in vitro study. J Investig Clin Dent 2019;e12400.

5. Abufarwa M, Noureldin A, Campbell PM, et al. The longevity of casein phosphopeptide-amorphous calcium phosphate fluoride varnish's preventative effects: Assessment of white spot lesion formation. Angle Orthod 2019;89:10-15.
6. Thakkar PJ, Badakar CM, Hugar SM, et al. An in vitro comparison of casein phosphopeptide-amorphous calcium phosphate paste, casein phosphopeptide-amorphous calcium phosphate paste with fluoride and casein phosphopeptide-amorphous calcium phosphate varnish on the inhibition of demineralization and promotion of remineralization of enamel. J Indian Soc Pedod Prev Dent 2017;35:312318.

7. Ancira-Gonzalez L, Esparza-Villalpando V, Garrocho-Rangel A, et al. White Spot Lesion Remineralisation Agents in Primary Teeth: A Systematic Review. Oral Health Prev Dent 2018;16:391-400.

8. Tuloglu N, Bayrak S, Tunc ES, et al. Effect of fluoride varnish with added casein phosphopeptide-amorphous calcium phosphate on the acid resistance of the primary enamel. BMC Oral Health 2016;16:103.

9. Duraisamy V, Xavier A, Nayak UA, et al. An in vitro evaluation of the demineralization inhibitory effect of $F(-)$ varnish and casein phosphopeptide-amorphous calcium phosphate on enamel in young permanent teeth. J Pharm Bioallied Sci 2015;7:S513-S517.

10. Bayrak S, Tuloglu N, Bicer $\mathrm{H}$, et al. Effect of Fluoride Varnish Containing CPP-ACP on Preventing Enamel Erosion. Scanning 2017;2017:1897825.

11. Yassaei S, Aghili H, Shahraki N, et al. Efficacy of erbium-doped yttrium aluminum garnet laser with casein phosphopeptide amorphous calcium phosphate with and without fluoride for remineralization of white spot lesions around orthodontic brackets. Eur J Dent 2018;12:210-216.

12. Reynolds EC, Cai F, Cochrane NJ, Shen P, Walker GD, Morgan MV, Reynolds C. Fluoride and casein phosphopeptide-amorphous calcium phosphate.J Dent Res 2008; 87:344-348.

13. Wang LJ, Tang R, Bonstein T, Bush P, Nancollas GH. Enamel demineralization in primary and permanent teeth.J Dent Res 2006;85:359-363.

14. $\mathrm{Hr} \mathrm{P}, \mathrm{Ra} \mathrm{H}, \mathrm{Re} \mathrm{H}$, et al. Concentration of Calcium, Phosphate and Fluoride lons in Microbial Plaque and Saliva after Using CPP-ACP Paste in 6-9 year-old Children. J Dent Biomater 2016;3:214-219.

15. Ivanoff CS, Hottel TL, Garcia-Godoy F. Microhardness recovery of demineralized enamel after treatment with fluoride gel or CPP-ACP paste applied topically or with dielectrophoresis. Am J Dent 2012; 25:109-113.

16. Prestes L, Souza BM, Comar LP, Salomão PA, Rios D, Magalhaes AC. In situ effect of chewing gum containing CPP-ACP on the mineral precipitation of eroded bovine enamel-a surface hardness analysis.J Dent. 2013 Aug; 41:747-751.

17. Jensen ME, Donly K, Wefel JS. Assessment of the effect of selected snack foods on the remineralization/demineralization of enamel and dentin. J Contemp Dent Pract 2000; 1:1-17.

18. De Menezes Oliveira MA, Torres CP, Gomes-Silva JM, Chinelatti MA, De Menezes FC, Palma-Dibb RG, Borsatto MC. Microstructure and mineral composition of dental enamel of permanent and deciduous teeth.Microsc Res Tech 2010; 73:572-577.

19. Khamverdi Z, Kordestani M, Panahandeh N, et al. Influence of $\mathrm{CO} 2$ Laser Irradiation and CPPACP Paste Application on Demineralized Enamel Microhardness. J Lasers Med Sci 2018;9:144-148.

20. Cuy JL, Mann AB, Livi KJ, Teaford MF, Weihs TP. Nanoindentation mapping of the mechanical properties of human molar tooth enamel. Arch Oral Biol 2002;47:281-291.

21. Dowker SE, Elliott JC, Davis GR, Wassif HS. Longitudinal study of the three-dimensional development of subsurface enamel lesions during in vitro demineralisation.Caries Res 2003;37:237-245.

22. Poureslami H, Hoseinifar R, Khazaeli $P$, et al. Changes in the Concentration of lons in Saliva and Dental Plaque after Application of CPP-ACP with and without Fluoride among 6-9 Year Old Children. J Dent Biomater 2017;4:361-366.

23. Cross KJ, Huq NL, Stanton DP, Sum M, Reynolds EC.NMR studies of a novel calcium, phosphate and fluoride delivery vehiclealpha(S1)-casein(59-79) by stabilized amorphous fluoride phosphate nanocomplexes. Biomaterials 2004;25:5061-5069.

24. Hicks J, Flaitz C.Role of remineralizing fluid in in vitro enamel caries formation and progression.Quintessence Int 2007; 38:313-319. 
25. Singh S, Singh SP, Goyal A, et al. Effects of various remineralizing agents on the outcome of post-orthodontic white spot lesions (WSLs): a clinical trial. Prog Orthod 2016;17:25.

26. Cabezas Gonzalez C. The chemistry of caries: remineralization and demineralization events with direct clinical relevance. Dent Clin North Am 2010; 54:469-478.

27. Pithon MM, Baiao FS, Sant'Anna LID, et al. Effectiveness of casein phosphopeptide-amorphous calcium phosphate-containing products in the prevention and treatment of white spot lesions in orthodontic patients: A systematic review. J Investig Clin Dent 2019; 12391

28. Driessens FC, Heijligers HJ, Borggreven JM, Wöltgens JH. Posteruptive maturation of tooth enamel studied with the electrone microprobe. Caries Res 1985; 19:390-395.

29. Jafari K, Hekmatfar S, Fereydunzadeh M. In vitro Comparison of Antimicrobial Activity of Conventional Fluoride Varnishes Containing Xylitol and Casein Phosphopeptide-Amorphous Calcium Phosphate. $J$ Int Soc Prev Community Dent 2018;8:309-313. 